\title{
Relative contribution of glycogenolysis and gluconeogenesis to hepatic glucose production in control and diabetic rats. A re-examination in the presence of euglycaemia
}

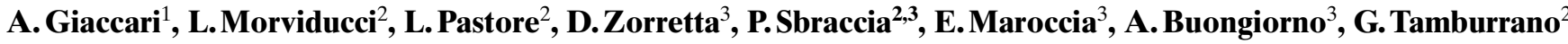 \\ ${ }^{1}$ Institute of Endocrinology, Catholic University, Rome, Italy \\ ${ }^{2}$ Division of Endocrinology, II Clinica Medica, Policlinico Umberto I, Rome, Italy \\ ${ }^{3}$ Laboratory of Clinical Biochemistry, Istituto Superiore di Sanità, Rome, Italy
}

\begin{abstract}
Summary Several studies have suggested that, in non-insulin-dependent diabetes mellitus, augmented gluconeogenesis is responsible for increased endogenous glucose production (EGP) and in the end determines fasting hyperglycaemia. However, human and animal studies have been conducted by comparing euglycaemic control subjects to hyperglycaemic diabetic probands. We measured EGP and hepatic gluconeogenesis comparing control and diabetic rats in the fasting state (with diabetic animals in hyperglycaemia), re-examining them in the presence of identical euglycaemia (with diabetic rats made acutely euglycaemic through i.v. phloridzin) or during a hyperinsulinaemic clamp. All rats were infused with [3$\left.{ }^{3} \mathrm{H}\right]$-glucose and $\left[\mathrm{U}_{-}{ }^{14} \mathrm{C}\right]$-lactate; the ratio between ${ }^{14} \mathrm{C}$-uridine-diphosphoglucose (reflecting ${ }^{14} \mathrm{C}$-glucose 6-phosphate) and $2 \cdot{ }^{14} \mathrm{C}$-phosphoenolpyruvate specific activities (both purified by high performance liquid chromatography from liver) measured hepatic gluconeogenesis. In diabetic animals, although overall EGP $\left(\sim 19.5 \mathrm{mg} \cdot \mathrm{kg}^{-1} \cdot \mathrm{min}^{-1}\right)$ remained unaffected by experimental euglycaemia, the contribution of
\end{abstract}

glycogenolysis largely increased (from 5.4 to $11.7 \mathrm{mg} \cdot \mathrm{kg}^{-1} \cdot \mathrm{min}^{-1}$, hyper- vs euglycaemia) while gluconeogenesis decreased (from 14.0 to $8.1 \mathrm{mg} \cdot \mathrm{kg}^{-1}$ $\left.\cdot \mathrm{min}^{-1}\right)$; both were responsible for the augmented EGP (control rats, EGP: $12.7 \mathrm{mg} \cdot \mathrm{kg}^{-1} \cdot \mathrm{min}^{-1}$; gluconeogenesis: $\quad 5.9 \mathrm{mg} \cdot \mathrm{kg}^{-1} \cdot \mathrm{min}^{-1}$; glycogenolysis: $\left.6.7 \mathrm{mg} \cdot \mathrm{kg}^{-1} \cdot \mathrm{min}^{-1}\right)$. Finally, during insulin clamp, gluconeogenesis and glycogenolysis were similarly decreased, and both contributed to the hepatic insulin-resistance of diabetic animals. We conclude that, in this model of non-insulin-dependent diabetes, augmented gluconeogenesis is not primarily responsible for fasting hyperglycaemia and hepatic insulin resistance. Finally, failure to accurately match the experimental conditions in which diabetic and control humans or animals are compared affects gluconeogenesis, overestimating its role in determining hyperglycaemia. [Diabetologia (1998) 41: 307-314]

Keywords Hepatic glucose production, gluconeogenesis, glycogenolysis, insulin resistance, fasting hyperglycaemia, glucose clamp.
Received: 10 September 1997 and in revised form: 13 November 1997

Corresponding author: Dr. A. Giaccari, Institute of Endocrinology, Policlinico A. Gemelli, Largo Agostino Gemelli 8, I00168, Rome, Italy

Abbreviations: EGP, Endogenous glucose production; HGP, hepatic glucose production; UDP-glucose, uridinediphosphoglucose; PEP, phosphoenolpyruvate; GN, gluconeogenesis; GL, hepatic glycogenolysis; GC, glucose cycling; NEFA, nonesterified fatty acids; sa, specific activity; NIDDM, non-insulin-dependent diabetes mellitus.
In non-insulin-dependent diabetes mellitus (NID$\mathrm{DM})$ endogenous glucose production (EGP) is increased [1-5] and is considered the major cause of fasting hyperglycaemia [6]. Increased hepatic glucose output could result from enhanced glycogenolysis, gluconeogenesis, or a combination of both. The inadequacy of methods to quantify gluconeogenesis has been a major impediment to addressing this issue. The splanchnic-balance technique cannot distinguish between hepatic and extrahepatic substrate uptake. Conventional isotopic methods using labelled threecarbon compounds or C-6 labelled glucose result in an underestimation of gluconeogenesis due to the 
loss of labelled carbons as $\mathrm{CO}_{2}$ within the Krebs cycle [7]. Consoli et al. [8], determining gluconeogenesis with infusion of $\left[2-{ }^{14} \mathrm{C}\right]$-acetate that allows an estimation of the Krebs cycle dilution, concluded that increased gluconeogenesis is the predominant mechanism responsible for increased hepatic glucose output in NIDDM. However Consoli et al. have also questioned the validity of the $\left[2-{ }^{14} \mathrm{C}\right]$-acetate infusion [9], for which several important assumptions must be satisfied before it can be accepted as a means to assess gluconeogenesis in vivo. At present, ${ }^{13} \mathrm{C} \mathrm{nu}-$ clear magnetic resonance (NMR) spectroscopy seems to be the most reliable method for indirect determination of gluconeogenesis in humans [10], although it is costly to reproduce. With such an approach, Magnusson et al. [11] found that total glucose production, measured with the infusion of [6${ }^{3} \mathrm{H}$ ]-glucose, was increased in NIDDM, and that gluconeogenesis accounted for almost the entire (88\%) rate of total glucose production. These data, however, were obtained by measuring the hepatic glycogen content after 16 and $23 \mathrm{~h}$ of fasting, and are mostly based on reduced glycogen concentration at the beginning of the study. No data are available for after an overnight fast.

Usually, in the attempt to delineate the mechanism(s) responsible for enhanced hepatic glucose production (HGP) in diabetes, comparisons have been made between normoglycaemic control subjects and hyperglycaemic diabetic subjects, also by Consoli and Magnusson [8,11-13]. However, it is now recognized that plasma glucose concentration per se regulates HGP [14-19], and due to the specific effects of hyperglycaemia on hepatic glucose fluxes, the relative contribution of the various metabolic pathways to enhanced HGP in diabetes may be influenced by either chronic alterations in hepatic glucose metabolism or acute metabolic conditions at the time of the experimental study. To simplify, several in vivo techniques (including the oral glucose tolerance test) may allow the role of reduced insulin action in diabetes to be studied, but only the accurate matching of glucose and insulin (i.e. the euglycaemic clamp technique) allows diabetic and control subjects to be compared most accurately.

The ideal protocol to study the mechanism(s) responsible for the increased HGP should, therefore, be performed without concomitant hyperglycaemia. Insulin administration might be used for this purpose. However insulin could inhibit HGP either through a direct hepatic action [20] or, indirectly, by reducing the availability of substrates and energy for gluconeogenesis [21]. Furthermore, peripheral insulin levels may control glucose production by their inhibitory effect on glucagon secretion [22] or NEFA availability [23]. Another way to achieve normoglycaemia in NIDDM patients is starvation, but this, again, largely modifies experimental conditions, making it incom- parable with the overnight fast. Phloridzin, which is an inhibitor of glucose reabsorption at the tubular level in the kidney, allows euglycaemia to be reached in diabetic rats through glycosuria [24, 25]. Unfortunately, it cannot be used on humans because of its side effects, but its use in animal models of diabetes may offer new insights in the understanding of the intrahepatic pathways responsible for fasting hyperglycaemia [26].

Ninety percent pancreatectomy on rats is an experimental model of NIDDM that has been widely studied [27-30]. By using these rats, a new approach for the evaluation of gluconeogenesis has been developed [31] through the use of a double tracer that allows the intracellular glucose 6-phosphate pool (in constant equilibrium with uridinediphosphate-glucose) to be estimated and, thereby, allowing calculation of the three pathways that contribute to this pool (glucose uptake from plasma, gluconeogenesis, glycogenolysis). With this method, correct measurement of gluconeogenesis and glycogenolysis can be performed.

The present study was therefore undertaken to quantify rates of net hepatic glycogenolysis and gluconeogenesis in $90 \%$ pancreatectomized and control rats, under conditions of matched euglycaemia obtained with phloridzin. Moreover, to delineate the impact of insulin on the pathways of HGP, studies with high physiological insulin concentrations were performed.

\section{Materials and methods}

Animals. Two groups of male Sprague-Dawley rats (Charles River Laboratories, Lecco, Italy) were studied: sham-operated control rats $(n=16)$ and partially pancreatectomized diabetic rats $(n=17)$. At $3-4$ weeks of age, the diabetic rats $(80-100 \mathrm{~g})$ were anaesthetized with phenobarbital $(50 \mathrm{mg} / \mathrm{kg}$ body weight i. p.) and $90 \%$ of their pancreas was removed according to the technique of Foglia [32], as modified by Bonner-Weir et al. [33], and as previously published [27, 29-31]. Immediately after the pancreatectomy, the rats were housed in individual cages in an air-controlled room, and were subjected to a standard 12-h light/dark cycle. As in prior studies [27, 29-31], the rats received rat chow and water in an amount that sustained normal growth in all animals. After surgery, the rats were weighed weekly and tail vein blood was collected for the determination of non-fasting plasma glucose and insulin concentrations at the same time (09.00 hours). Five to 7 days before the experiment (5-6 weeks after pancreatectomy for diabetic rats, and at 910 weeks of age for all rats), all the animals were anaesthetized with an intraperitoneal injection of pentobarbital $(50 \mathrm{mg} / \mathrm{kg}$ body weight), and indwelling catheters were inserted into the right jugular vein and the left carotid artery. The venous catheter was extended to the level of the right atrium, and the arterial catheter was advanced to the level of the aortic arch. Both catheters were filled with heparin/polyvinilpyrrolidone solution, sealed, tunneled subcutaneously around the side of the neck and exteriorized through a skin incision [27, 29-31, 34]. 
Studies. All studies were conducted in the afternoon, after a 6-h fast. Throughout the studies, the rats were awake, and allowed to move freely within the confines of a large cage, with the connecting tubing suspended overhead. The venous catheters were used for blood withdrawal, while the arterial catheters were used for the infusion of the test substances. To prevent intravascular volume depletion and anaemia, fresh whole blood obtained by heart puncture from fasting littermates of the test animal was administered at a constant rate, designed to quantitatively replace the total blood loss during the study [27, 29-31, 34]. Before the beginning of any other infusion, 12 of the $17 \mathrm{di}-$ abetic animals received an acute i.v. treatment with phloridzin for 2-3 h, until euglycaemia was reached. The remaining 5 diabetic rats were infused with saline instead of phloridzin, in order to maintain spontaneous hyperglycaemia. Glucose metabolism was then measured with an infusion of $\left[3-{ }^{3} \mathrm{H}\right]$-glucose followed by a bolus of $\left[\mathrm{U}_{-}{ }^{14} \mathrm{C}\right]$-lactate, as previously described [14]. Briefly, all animals received a prime/continuous $(\sim 1 \mu \mathrm{Ci} /$ min) infusion of $\left[3-{ }^{3} \mathrm{H}\right]$-glucose (Du Pont New England Nuclear, Milan, Italy) for $2 \mathrm{~h}$ [14]. Plasma samples for the determination of $\left[3-{ }^{3} \mathrm{H}\right]$-glucose and tritiated water specific activities were obtained at 5-10 min intervals throughout the study. Ten minutes before being killed, all animals received a bolus of $\left[\mathrm{U}-{ }^{14} \mathrm{C}\right]$-lactate $(\sim 100 \mu \mathrm{Ci})$. Except for the animals studied in simple fasting state (i.e. just tracers and saline), all animals received a prime/continuous infusion of insulin (Bio-Insulin R, Laboratori Guidotti, Pisa, Italy) at 0.5 (to replace endogenous insulin and match the fasting insulin concentration) or $4 \mathrm{mU} \cdot \mathrm{kg}^{-1} \cdot \mathrm{min}^{-1}$ for $2 \mathrm{~h}$. A variable infusion of $25 \%$ glucose solution was started at time 0 and adjusted in order to clamp the plasma glucose concentration at approximately $6.7 \mathrm{mmol} /$ 1. Octreotide (Italfarmaco, Milan, Italy), a long-acting somatostatin analogue, was infused throughout the latter insulin studies at a rate of $100 \mathrm{ng} \cdot \mathrm{kg}^{-1} \cdot \mathrm{min}^{-1}$. and endogenous glucagon was replaced by a glucagon infusion of $0.3 \mathrm{ng} \cdot \mathrm{kg}^{-1} \cdot \mathrm{min}^{-1}$ (Glucagone Novo; Novo-Nordisk, Bagsvaerd, Denmark). Plasma samples for the determination of plasma insulin concentrations were obtained at time $-20,0,90,120 \mathrm{~min}$. At the end of the 120-min infusions, all the rats were injected intravenously with pentobarbital $(60 \mathrm{mg} / \mathrm{kg}$ body weight $)$, their abdomens were quickly opened, the rectus abdominal muscles were freeze-clamped in situ, urine samples were collected, and then the livers and the hindlimb muscles were freeze-clamped with aluminium tongs pre-cooled in liquid nitrogen. All tissue samples were kept frozen at $-80^{\circ} \mathrm{C}$ for subsequent analysis.

Whole body glucose uptake. Data for total body glucose uptake and HGP represent the mean values during the last $30 \mathrm{~min}$. Total body glucose disposal was calculated by adding the rate of HGP during each insulin clamp to the glucose infusion rate during the same time period, and then subtracting glycosuria $[27,29-31,34]$.

Glycogen formation in vivo. Muscle glycogen synthesis was quantified during the $4 \mathrm{mU}$ clamp by measuring the incorporation of $\left[3-{ }^{3} \mathrm{H}\right]$-glucose counts into glycogen $[27,29-31,34]$. The frozen muscle samples were homogenised in $0.3 \mathrm{~mol} / \mathrm{l}$ perchloric acid (1/4), and in aliquots of the tissue homogenate glycogen was precipitated by washing in 10 volumes of absolute ethanol and by incubating for $1 \mathrm{~h}$ at $-20^{\circ} \mathrm{C}$. The procedure was repeated three times and then the precipitate was collected, dried and dissolved in water before scintillation counting. The recovery of free $\left[3-{ }^{3} \mathrm{H}\right]$-glucose, added to test the procedure, was less than $1 \%$ of the free glucose radioactivity added to the homogenate in each assay. The rate of net glycogen synthesis was calculated by dividing the amount of $\left[3-{ }^{3} \mathrm{H}\right]$-glucose incorporated in glycogen (dpm per $\mathrm{g}$ of muscle tissue) by the time-weighed mean plasma $\left[3-{ }^{3} \mathrm{H}\right]$-glucose specific activity $(\mathrm{dpm} / \mathrm{mg}$ glucose $)$. In each rat, three separate determinations on hindlimb muscle tissue were averaged in order to approximate the mean whole body muscle glycogen synthesis.

Whole body glycolytic flux in vivo. Aliquots of the plasma were precipitated with $\mathrm{Ba}(\mathrm{OH})_{2}$ and $\mathrm{ZnSO}_{4}$ and centrifuged. Plasma tritiated water specific activity was determined by liquid scintillation counting of the protein-free supernatant (Somogyi filtrate) before and after evaporation to dryness. Because tritium on the C-3 position of glucose is lost to water during glycolysis, it can be assumed that plasma tritium is present either in tritiated water or $\left[3-{ }^{3} \mathrm{H}\right]$-glucose. Plasma water was assumed to be $93 \%$ of the total plasma volume and the total body water mass was assumed to be $65 \%$ of the body mass. The whole body glycolytic rate was calculated from the increment per min in plasma ${ }^{3} \mathrm{H}_{2} \mathrm{O}$ radioactivity from 60 to 120 min multiplied by the body water space and divided by the $\left[3-{ }^{3} \mathrm{H}\right]$-glucose specific activity [27, 29-31, 34].

Endogenous glucose production. EGP was calculated by subtracting cold glucose infusion during the last $30 \mathrm{~min}$ of each clamp from the glucose rate of appearance (ratio of the [3$\left.{ }^{3} \mathrm{H}\right]$-glucose infusion rate and the $\left[3-{ }^{3} \mathrm{H}\right]$-glucose specific activity) calculated during the same time period.

Gluconeogenesis was measured from the hepatic specific activities of ${ }^{14} \mathrm{C}$-labelled uridinediphospho-glucose (UDP-glucose) and phosphoenolpyruvate (PEP), ${ }^{3} \mathrm{H}$-labelled UDPglucose and steady-state plasma $\left[3-{ }^{3} \mathrm{H}\right]$-glucose following the infusion of $\left[\mathrm{U}_{-}{ }^{14} \mathrm{C}\right]$-lactate and $\left[3-{ }^{3} \mathrm{H}\right]$-glucose. UDP-glucose specific activities (both ${ }^{14} \mathrm{C}$ and ${ }^{3} \mathrm{H}$ ) are assumed to reflect glucose 6-phosphate specific activities, as previously demonstrated in similar experiments $[14,31]$. HGP derives from two pathways, gluconeogenesis and glycogenolysis. The hepatic glucose 6phosphate pool, however, is also generated from a third major pathway, i.e. glucose coming from plasma. $\left[3-{ }^{3} \mathrm{H}\right]$-glucose keeps its label through the cycle glucose $\rightarrow$ glucose 6-phosphate $\rightarrow$ glucose, therefore, this pathway is not included in the measurement of HGP with $\left[3-{ }^{3} \mathrm{H}\right]$-glucose infusion; however, since our calculations are based on the dilution of the hepatic glucose 6-phosphate pool, glucose recycling from plasma must be considered. The relative contribution of plasma glucose to the glucose 6-phosphate pool (\%GC) is measured by the dilution of ${ }^{3} \mathrm{H}$-UDP-glucose (ratio of ${ }^{3} \mathrm{H}$-UDP-glucose and plasma $\left[3-{ }^{3} \mathrm{H}\right]$-glucose specific activities); this percentage also represents the relative contribution of plasma glucose to the overall glucose flux from the liver, i.e. glucose recycle. The relative contribution of gluconeogenesis to the glucose 6phosphate pool $(\% \mathrm{GN})$ is measured by the dilution of ${ }^{14} \mathrm{C}$ UDP-glucose (ratio of ${ }^{14} \mathrm{C}$-UDP-glucose and $2 \cdot{ }^{14} \mathrm{C}$-PEP specific activities, where the 2 - constant corrects the different number of labelled carbons in PEP and UDP-glucose). The relative contribution of glycogenolysis to the glucose 6-phosphate pool $(\% \mathrm{GL})$ is measured by difference from unit. The sum of the relative contribution of gluconeogenesis (\%GN) and glycogenolysis (\%GL) is equal to the relative contribution of HGP (\%HGP) to the overall hepatic glucose output (which also includes glucose recycling); therefore, actual gluconeogenesis is calculated as

Gluconeogenesis $=\mathrm{HGP} \cdot(\% \mathrm{GN} / \% \mathrm{HGP})$; substituted by the equations reported in the text

Gluconeogenesis $=$

HGP $\cdot{ }^{14} \mathrm{C}$-UDP-glucose sa $\cdot{ }^{3} \mathrm{H}$-glucose sa

$\overline{2 \cdot{ }^{14} \mathrm{C} \text {-PEP sa } \cdot\left({ }^{3} \mathrm{H} \text {-glucose sa }-{ }^{3} \mathrm{H} \text {-UDP-glucose sa) }\right.}$ 
Table 1. General characteristics of the animals

\begin{tabular}{lcc}
\hline Group & Control rats & Diabetic rats \\
\hline Body weight $(\mathrm{g})$ & $262 \pm 8$ & $249 \pm 13$ \\
Fasting plasma glucose $(\mathrm{mmol} / \mathrm{l})$ & $6.5 \pm 0.3$ & $13.6 \pm 2.6^{\mathrm{a}}$ \\
Fasting plasma insulin $(\mathrm{pmol} / \mathrm{l})$ & $76 \pm 12$ & $59 \pm 10$ \\
Fed plasma glucose $(\mathrm{mmol} / \mathrm{l})$ & $8.5 \pm 0.5$ & $18.6 \pm 1.6^{\mathrm{a}}$ \\
Fed plasma insulin $(\mathrm{pmol} / \mathrm{l})$ & $155 \pm 14$ & $88 \pm 10^{\mathrm{a}}$ \\
\hline
\end{tabular}

a $2 p<0.05$ or less as compared to the control animals

Table 2. Steady state plasma glucose and insulin levels during the studies

\begin{tabular}{llllll}
\hline & \multicolumn{2}{l}{ Glucose $(\mathrm{mmol} / \mathrm{l})$} & & \multicolumn{2}{l}{ Insulin $(\mathrm{pmol} / \mathrm{l})$} \\
\cline { 2 - 3 } \cline { 5 - 6 } & $\begin{array}{l}\text { Control } \\
\text { rats }\end{array}$ & $\begin{array}{l}\text { Diabetic } \\
\text { rats }\end{array}$ & $\begin{array}{l}\text { Control } \\
\text { rats }\end{array}$ & $\begin{array}{l}\text { Diabetic } \\
\text { rats }\end{array}$ \\
\hline Saline studies & $6.8 \pm 0.4$ & $17.7 \pm 1.7^{\text {ab }}$ & $74 \pm 9$ & $61 \pm 11$ \\
Euglycaemia & $6.8 \pm 0.2$ & $6.7 \pm 0.2$ & $68 \pm 5$ & $64 \pm 4$ \\
Insulin clamp & $6.6 \pm 0.2$ & $6.7 \pm 0.1^{\mathrm{c}}$ & & $584 \pm 40^{\mathrm{bc}}$ & $535 \pm 34^{\mathrm{bc}}$ \\
\hline
\end{tabular}

a $2 p<0.05$ or less as compared to the control animal within the same study protocol; ${ }^{\mathrm{b}} 2 p<0.05$ or less as compared to the euglycaemic studies within the same group; ${ }^{c} 2 p<0.05$ or less as compared to the saline studies within the same group

Data [35], recently reviewed [36], but not uniformly confirmed [37], make apparent a role for the kidneys in tracer-derived glucose rate of appearance. The eventual role of the kidney in diluting tritiated glucose cannot be calculated in these studies; however, if the rat kidneys actually produce glucose (even after a fast as short as $6 \mathrm{~h}$ ) this production does not affect our calculations on the relative contribution of hepatic gluconeogenesis and glycogenolysis, since they are calculated on intrahepatic specific activities.

Analytical procedures. Plasma glucose was measured by means of the glucose oxidase method (Glucose Analyzer II; Beckman Instruments, Milan, Italy) and plasma insulin by radioimmunoassay, using rat or human insulin standards (Rat insulin RIA kit - highly sensitive; Novo-Nordisk). Glucose 6-phosphate was measured spectrophotometrically in liver, as described by Michal [38]. Glycogen concentrations were determined following digestion with amyloglucosidase as previously described [34]. Plasma non-esterified fatty acid concentrations (NEFA) were measured using an acyl-CoA oxidase colorimetric kit (Boehringer Mannheim, Milan, Italy). Plasma $\left[3-{ }^{3} \mathrm{H}\right]-$ glucose radioactivity was measured on the supernatants of barium hydroxide-zinc sulphate precipitates (Somogyi procedure) of plasma samples after evaporation to dryness, to eliminate tritiated water [34]. UDP-glucose and PEP specific activities in the liver were obtained through two sequential chromatographic separations, as previously reported [31, 39]. Briefly, the first was performed on a solid-phase, strong anion-exchange cartridge, with the use of phosphate buffers of increasing molarity. This first purification allows for the partial separation of the two compounds of interest from all non-polar and most polar intracellular substrates, with optimal recoveries. The second step is a reversed phase, ion-pairing HPLC isocratic method, on a $\mathrm{C}_{18}$ column.

Statistical analysis. All values are presented as mean \pm SEM. Differences between groups were determined using Student's $t$-test for unpaired data.

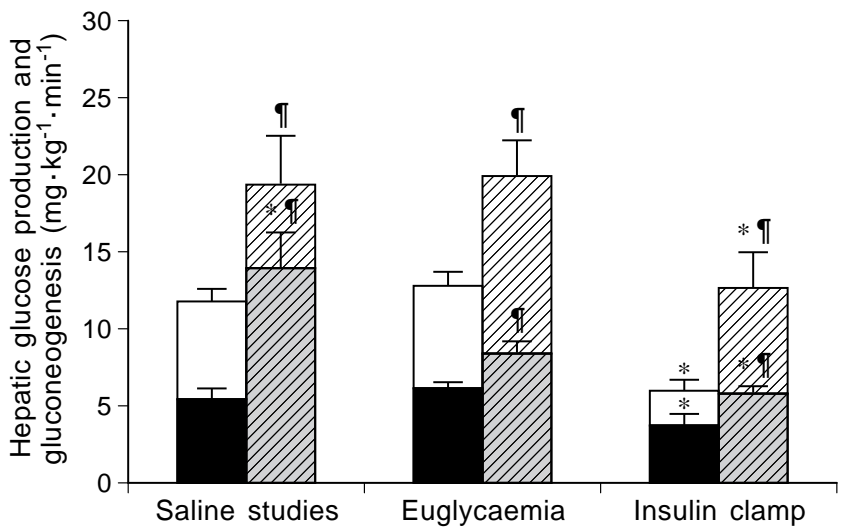

Fig. 1. Overall hepatic glucose production (whole bar) and gluconeogenesis (dark, lower bar) in control (empty/full bars) and diabetic (cross hatched bars) rats. In saline studies, animals were compared with their own fasting glycaemia. In euglycaemic studies, diabetic rats were infused with phloridzin to match plasma glucose of control animals. The last two bars show results obtained at the end of the hyperinsulinaemic clamp. $* 2 p<0.05$ or less as compared to the euglycaemic studies (the two middle bars) within the same group. $2 p<0.05$ or less as compared to the control animal within the same study protocol

\section{Results}

General characteristics of the animals. (Table 1). There were no differences in the mean body weight between control and diabetic rats. Both the fasting and post-meal plasma glucose concentrations during the 2-week period before the studies were significantly higher in the diabetic compared to the control group. The fasting plasma insulin concentrations were similar, whereas the post-meal plasma insulin concentrations were significantly diminished in diabetic rats compared to controls. Steady-state plasma glucose and insulin concentrations during the studies were similar in the two groups, except for saline-infused diabetic animals (Table 2). Steady-state conditions for both plasma glucose concentration and specific activity were reached within approximately $30 \mathrm{~min}$. The coefficient of variation in the plasma glucose level was less than $5 \%$ in all studies.

Saline studies. When compared to euglycaemic, saline $(154 \mathrm{mmol} / \mathrm{l} \mathrm{NaCl})$-infused control rats, the diabetic animals studied in the presence of hyperglycaemia showed a marked increase in the rate of EGP $\left(19.4 \pm 3.2\right.$ vs $11.8 \pm 0.8 \mathrm{mg} \cdot \mathrm{kg}^{-1} \cdot \mathrm{min}^{-1} ; \quad p<0.05$; Fig. 1, two left bars). PEP-gluconeogenesis contributed to $72.2 \pm 5.8 \%$ of the increased HGP of diabetic rats, while it contributed to only $45.2 \pm 3.7 \%$ of the HGP in the matched, saline-infused control animals $(p<0.01$, Fig. 2). As a consequence, HGP from glycogenolysis was similar between the two groups $\left(5.5 \pm 1.3\right.$ and $6.4 \pm 0.5 \mathrm{mg} \cdot \mathrm{kg}^{-1} \cdot \mathrm{min}^{-1}$, respectively, in saline-infused diabetic and control rats). No cold glucose was infused in any rat, and glycosuria in dia- 


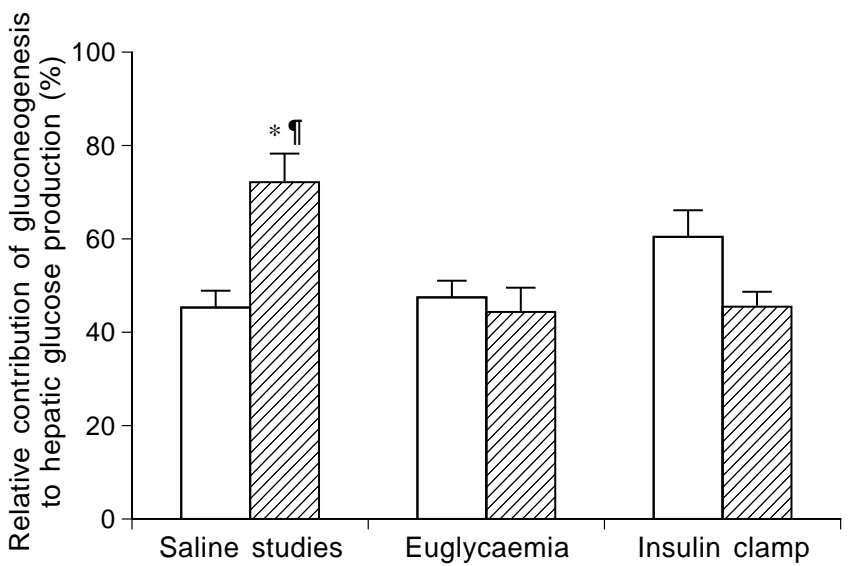

Fig. 2. Relative contribution of gluconeogenesis to overall hepatic glucose production in control (empty bars) and diabetic rats (cross hatched bars). In saline studies, animals were compared with their own fasting glycaemia. In euglycaemic studies, diabetic rats were infused with phloridzin to match plasma glucose of control animals. The last two bars show results obtained at the end of the hyperinsulinaemic clamp. $* 2 p<0.05$ or less as compared to the euglycaemic studies (the two middle bars) within the same group. $2 p<0.05$ or less as compared to the control animal within the same study protocol

betic animals was quantitatively small (always less than $0.5 \mathrm{mg} \cdot \mathrm{kg}^{-1} \cdot \mathrm{min}^{-1}$ ); therefore, rates of glucose uptake in diabetic rats were increased as well ( $p<0.05$, Fig. 3, two left bars).

Insulin replacement, euglycaemic studies. In this set of experiments, diabetic rats were made acutely euglycaemic with phloridzin, while endogenous insulin was replaced by $0.5 \mathrm{mU} \cdot \mathrm{kg}^{-1} \cdot \mathrm{min}^{-1}$ of exogenous insulin in all animals. In control animals, the replacement of endogenous insulin did not modify either the EGP $\left(12.7 \pm 0.7 \mathrm{mg} \cdot \mathrm{kg}^{-1} \cdot \mathrm{min}^{-1}\right)$ or the relative contribution of gluconeogenesis $(47.2 \pm 2.7 \%$, Figs. 1 and 2). No cold glucose was infused; therefore, overall glucose uptake matched the results obtained in saline-infused control rats (Fig. 3). In diabetic rats, the presence of acute euglycaemia (reached with phloridzin) did not modify the overall EGP obtained in saline-infused hyperglycaemic animals (19.8 \pm $\left.2.3 \mathrm{mg} \cdot \mathrm{kg}^{-1} \cdot \mathrm{min}^{-1}\right)$. Gluconeogenesis, however, was largely inhibited, and contributed to only $43.9 \pm$ $5.2 \%(p<0.01$ vs hyperglycaemic, diabetic rats) to the overall HGP (Fig.2). Glucose uptake also decreased, reaching fluxes slightly smaller than those obtained in the matched insulin-replaced control animals $\left(10.3 \pm 0.9 \mathrm{mg} \cdot \mathrm{kg}^{-1} \cdot \mathrm{min}^{-1}\right)$ (Fig. 3).

Hyperinsulinaemic, euglycaemic clamp studies. Hyperinsulinaemia determined a reduction of EGP in both diabetic and control rats (Fig. 1); however, this suppression was about $54 \%$ in control and $37 \%$ in diabetic rats $\left(12.5 \pm 0.7 \mathrm{vs} 5.8 \pm 0.7 \mathrm{mg} \cdot \mathrm{kg}^{-1} \cdot \mathrm{min}^{-1}\right.$, diabetic vs control animals; $p<0.01)$. Insulin infusion

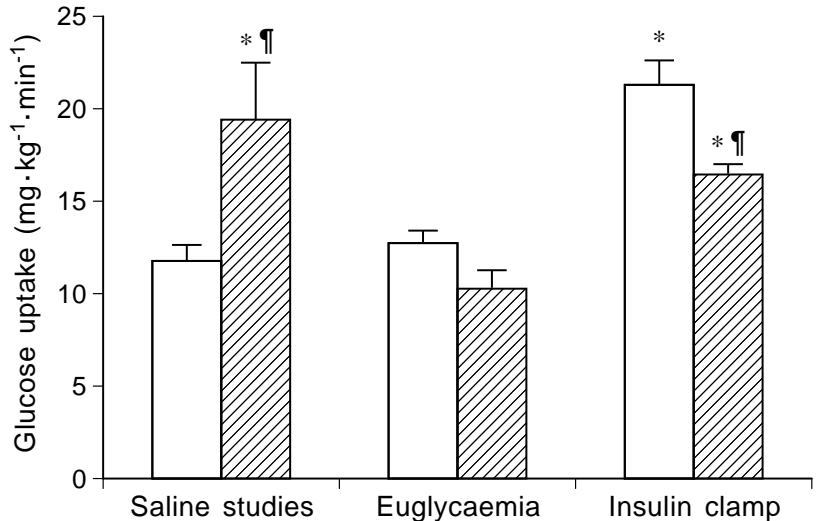

Fig. 3. Glucose uptake in control (empty bars) and diabetic rats (cross hatched bars). In saline studies, animals were compared with their own fasting glycaemia. In euglycaemic studies, diabetic rats were infused with phloridzin to match plasma glucose of control animals. The last two bars show results obtained at the end of the hyperinsulinaemic clamp. $* 2 p<0.05$ or less as compared to the euglycaemic studies (the two middle bars) within the same group. $2 p<0.05$ or less as compared to the control animal within the same study protocol

determined a relative increase of gluconeogenesis only in control rats; such an increase, however, was not statistically significant ( $59.8 \pm 6.0$ vs $45.2 \pm 3.3 \%$, $p$ : NS, Fig. 2). Consistent with these findings, the suppressive effect of insulin on hepatic glycogenolysis was more evident in control than in diabetic rats. When the relationship between glycogenolysis and gluconeogenesis was examined in terms of actual fluxes (i.e. in $\mathrm{mg} \cdot \mathrm{kg}^{-1} \cdot \mathrm{min}^{-1}$ ) in diabetic rats, both the increase of glycogenolysis and gluconeogenesis contributed to enhanced HGP during insulin infusion as well (Fig.1). Hyperinsulinaemia increased glucose utilization in both groups, although in diabetic rats it was still reduced compared to controls $(16.5 \pm 0.5$ vs $21.3 \pm 1.3 \mathrm{mg} \cdot \mathrm{kg}^{-1} \cdot \mathrm{min}^{-1} ; p<0.01$, Fig. 3). The glycolytic rate was estimated from the appearance of tritiated water in plasma water after the infusion of [3${ }^{3} \mathrm{H}$ ]-glucose during the last $60 \mathrm{~min}$ of each study, and accounted for approximately $75 \%$ of overall glucose uptake in both control rats $\left(15.7 \pm 1.1 \mathrm{mg} \cdot \mathrm{kg}^{-1}\right.$ - $\left.\min ^{-1}\right)$ and diabetic rats $\left(12.8 \pm 0.6 \mathrm{mg} \cdot \mathrm{kg}^{-1} \cdot \mathrm{min}^{-1}\right)$, therefore with a reduction in diabetic animals $(p<0.05)$. Skeletal muscle glycogen synthesis accounted for the remaining approximately $25 \%$ of the overall glucose uptake, although it was markedly reduced in diabetic animals $(5.5 \pm 1.0$ vs $2.9 \pm 0.6 \mathrm{mg} \cdot \mathrm{kg}^{-1} \cdot \mathrm{min}^{-1}$, control and diabetic rats, respectively, $p<0.05$ ).

NEFA, hepatic glucose-6-phosphate and glycogen. Plasma NEFA concentrations were similar in salineinfused control and diabetic rats, and remained unaffected by insulin replacement (Table 3 ). At the end of the hyperinsulinaemic clamp, plasma NEFA was largely reduced in both groups, though it was higher 
Table 3. Non-esterified fatty acid concentrations in plasma, hepatic glucose 6-phosphate and glycogen measured at the end of the studies

\begin{tabular}{|c|c|c|c|c|c|c|}
\hline & \multicolumn{2}{|c|}{ Plasma NEFA $(\mu \mathrm{mol} / \mathrm{l})$} & \multicolumn{2}{|c|}{ Hepatic glucose 6-phosphate (nmol/g w.w.) } & \multicolumn{2}{|c|}{ Hepatic glycogen (mg/g w. w.) } \\
\hline & Control & Diabetic & Control & Diabetic & Control & Diabetic \\
\hline Saline studies & $1,018 \pm 121$ & $1,124 \pm 134$ & $521 \pm 22$ & $384 \pm 19^{\mathrm{a}}$ & $15.3 \pm 1.7$ & $21.3 \pm 2.8$ \\
\hline Euglycaemia & $1,180 \pm 141$ & $1,074 \pm 161$ & $508 \pm 27$ & $342 \pm 23^{a}$ & $14.7 \pm 1.6$ & $19.4 \pm 2.7$ \\
\hline Insulin clamp & $415 \pm 72^{\mathrm{bc}}$ & $680 \pm 98^{\mathrm{bc}}$ & $412 \pm 16^{\mathrm{bc}}$ & $328 \pm 18^{\mathrm{ab}}$ & $15.1 \pm 1.4$ & $20.1 \pm 2.5$ \\
\hline
\end{tabular}

a $2 p<0.05$ less as compared to the control animal within the same study protocol; ${ }^{\mathrm{b}} 2 p<0.05$ or less as compared to the euglycaemic studies within the same group; ${ }^{c} 2 p<0.05$ or less as compared to the saline studies within the same group

in diabetic animals. Glucose 6-phosphate concentration in the liver was reduced in diabetic animals, unchanged during the insulin-replacement studies and reduced at the end of the insulin clamp in both groups (Table 3). Hepatic glycogen was increased in diabetic animals in all studies. No changes were induced by exogenous insulin administration in all groups (Table 3 ).

\section{Discussion}

In patients with NIDDM, fasting hyperglycaemia derives from excessive endogenous glucose production (EGP) [1-6]. Quantification of the rate of gluconeogenesis suggests that the increased EGP is entirely caused by augmented gluconeogenesis [8, 11, 12]. Although it has been acknowledged that circulating plasma glucose concentration plays a major role in the regulation of hepatic glucose production (HGP) and its pathways [14-19], all the studies demonstrating increased gluconeogenesis compared diabetic and control subjects under different glycaemic conditions, and therefore did not consider the potential role of plasma glucose concentration per se in the regulation of the pathways of HGP. Thus, the present study examined the role of gluconeogenesis and glycogenolysis in the increased HGP of conscious diabetic rats without interfering hyperglycaemia.

In our first set of experiments (simple tracer infusion, Figs. 1 and 2, two left bars), it was evident that the rate of hepatic glycogenolysis in hyperglycaemic diabetic rats was similar to the rate of control animals; instead gluconeogenesis was largely increased (2-3 fold), and was responsible for all of the augmented overall HGP, therefore closely resembling the data obtained in human diabetes $[8,11,12]$. Interestingly, both fasting plasma NEFA and insulin, the major variables influencing gluconeogenesis and HGP, were similar between the two groups (Tables 2 and 3 ), thus suggesting a primitive effect of gluconeogenesis per se in determining fasting hyperglycaemia in diabetes.

In order to repeat the studies in the presence of identical euglycaemia, we performed a second set of experiments in which diabetic rats were acutely treated with phloridzin before the beginning of the infusion of the tracers. This drug largely inhibits the reabsorption of the filtered glucose in the kidney, determining massive glycosuria, but has no effects on skeletal muscle and the liver [24-26]; therefore, all the changes produced by phloridzin are due to reduced plasma glucose concentrations. Changes in glycaemia, however, could modify plasma insulin: therefore we also replaced insulin secretion by an insulin infusion that closely matched endogenous plasma insulin in the fasting state (Table 2). In this set of experiments (Figs. 1 and 2), both the overall HGP and gluconeogenesis of control animals closely reproduced the fluxes obtained after the simple fasting state (i.e. saline studies), thus suggesting that the octreotide/insulin/glucagon infusion had only minor, if any, effect on the pathways regulating HGP. In diabetic animals, however, although plasma insulin was accurately matched with the first set of experiments, gluconeogenesis largely decreased, while HGP remained mostly unaffected (Figs. 1 and 2). Therefore, in hyperglycaemic diabetic animals, hyperglycaemia was not only a consequence, but also a cause of increased gluconeogenesis.

Previous data in this animal model of diabetes [14] provided evidence that the activity of glucose 6-phosphatase, the enzyme responsible for de-phosphorylation of glucose 6-phosphate to glucose, is 2-3 fold increased, and is most probably the rate-limiting step for overall glucose output. Our data are consistent with such an hypothesis, also bearing in mind that glucose cycling in the liver is reduced. An increase in the activity of glucose 6-phosphatase, however, should also take into account the role of the GLUT2 glucose transporter, responsible for overall glucose uptake and release through the plasma membrane of the hepatic tissue [40]. An increase in the GLUT2 mRNA $[41,42]$ as well as in GLUT2 protein has been observed in the livers of streptozotocin diabetic rats, suggesting the permissive role of this transporter to the enhanced hepatic glucose output from the diabetic liver [41]. Consistently, in vitro [43, 44] and, more recently, in vivo $[44,45]$ experiments demonstrated that the GLUT2 gene expression is increased by high glucose levels. 
The mechanism(s) underlying the switch from gluconeogenesis to glycogenolysis in the presence of euglycaemia cannot be completely defined in the present studies. Plasma glucose concentration, however, is a potent modulator of glycogen metabolism in the liver, with hyperglycaemia inhibiting glycogen phosphorylase and stimulating glycogen synthase $[14,46$, 47]. In hyperglycaemic, diabetic animals, although the balance of hepatic glycogen is still of net breakdown, the presence of hyperglycaemia largely inhibits glycogenolysis, allowing gluconeogenesis to become the major pathway in contributing to HGP [29]. When euglycaemia is restored through phloridzin, however, glycogenolysis is not inhibited, and becomes co-responsible for increased HGP. Therefore, our data strongly suggest that the large increase of gluconeogenesis in hyperglycaemic diabetic animals is not primarily responsible for the increase in HGP, but is simply a consequence of an inhibition of prevailing hyperglycaemia.

These data were obtained in an animal model of diabetes; it is therefore not possible to apply them to human diabetes. However, data obtained in humans by Puhakainen et al. [48], suggest that a similar mechanism is also present in NIDDM patients. In their series of experiments, NIDDM patients were acutely treated with an ethanol infusion in order to inhibit gluconeogenesis. Although there was a $71 \%$ inhibition of gluconeogenesis from lactate and $65 \%$ from glycerol, total HGP was not reduced. Consistent with this report, the same authors used acipimox to inhibit lipolysis in another series of experiments [49] and, once again, obtained a decrease of gluconeogenesis (through the reduction of plasma NEFA) but no significant modifications of HGP in NIDDM patients. In both studies, gluconeogenesis was only minimally estimated (i.e. ${ }^{14} \mathrm{C}$-PEP dilution was not considered) and even though a direct effect of ethanol or acipimox in changing the metabolic milieu within the liver may not be excluded, these human data suggested, and we confirmed, that gluconeogenesis is not primarily responsible for diabetic hyperglycaemia.

We also aimed to evaluate the role of insulin in inhibiting HGP and its pathways, as assessed during a glucose clamp with physiological insulin. As expected, when compared to control animals, diabetic rats showed reduced suppression of HGP, either in relative terms or in absolute fluxes. When examining the role of gluconeogenesis and glycogenolysis in their contribution to such an increase, however, particular attention must be paid to the metabolic conditions of the compared groups. In fact, if the hyperinsulinaemic (clamped) diabetic animals are compared to their hyperglycaemic counterparts, a major reduction of gluconeogenesis is revealed, due to the inhibition from 72.2 to $45.2 \%$ or, more significantly, from 13.9 to $5.6 \mathrm{mg} \cdot \mathrm{kg}^{-1} \cdot \mathrm{min}^{-1}(p<0.01)$. This would lead to the speculation that hyperinsulinaemia is able to markedly lower gluconeogenesis, claiming a role of relative hypoinsulinaemia (insulin resistance) in increasing gluconeogenesis, HGP and, finally, plasma glucose. A completely different picture is observed when clamped diabetic rats are compared to their euglycaemic counterparts. In such cases, gluconeogenesis decreases from 8.3 to $5.6 \mathrm{mg} \cdot \mathrm{kg}^{-1} \cdot \mathrm{min}^{-1}$ $(p<0.05)$, with a reduction similar to the one observed in hepatic glycogenolysis (from 11.5 to $6.8 \mathrm{mg} \cdot \mathrm{kg}^{-1} \cdot \mathrm{min}^{-1}$ ), with actually a small increase in relative terms (from 47 to $60 \%, p=\mathrm{NS}$ ).

It therefore seems clear that the experimental conditions are of critical importance in examining the pathways responsible for the augmented HGP in diabetes. We conclude that gluconeogenesis is increased in hyperglycaemic diabetic animals, but is not primarily responsible for hyperglycaemia. Finally, when diabetic rats are compared to control animals in the presence of identical euglycaemia, both glycogenolysis and gluconeogenesis contribute to increased HGP in the fasting state and to reduced suppression by insulin. Although these results were obtained in an experimental model of diabetes, we believe that failure to accurately match the experimental conditions in which diabetic and control humans (as well as animals) are compared affects gluconeogenesis, overestimating its role in determining hyperglycaemia. From a clinical perspective, the relative role of gluconeogenesis in human NIDDM should be reevaluated.

Acknowledgements. The authors wish to thank Ms. F. Zorretta for excellent technical assistance and Ms. E. Benelli and Ms. N. Wright for expert secretarial assistance. This work was supported in part by grants from the Istituto Superiore di Sanità (Progetto Sindromi Ipoglicemiche, to A. B.) and from the Centro Internazionale Studi Diabete (to G. T.). When this work was initiated, A. G. had been granted a PGF Award from the Juvenile Diabetes Foundation International (file number 393323). L. M. has been granted a fellowship (dottorato di ricerca) from the "La Sapienza" Rome University.

\section{References}

1. DeFronzo RA, Simonson D, Ferrannini E (1982) Hepatic and peripheral insulin resistance: a common feature of type II (non-insulin-dependent) and type I (insulin-dependent) diabetes mellitus. Diabetologia 23: 313-319

2. Best JD, Judzewitach RG, Pfeifer MA, Beard JC, Halter JB, Porte D Jr (1982) The effect of chronic sulphonylurea therapy on hepatic glucose production in non-insulin-dependent diabetes. Diabetes 31: 333-338

3. Campbell P, Mandarino L, Gerich J (1988) Quantification of the relative impairment in actions of insulin on hepatic glucose production and peripheral glucose upake in non-insulin-dependent diabetes mellitus. Metabolism 37: 15-22

4. Bogardus C, Lillioja S, Howard BV, Reaven G, Mott D (1984) Relationship between insulin secretion, insulin action and fasting plasma glucose concentration in nondiabetic and non-insulin-dependent diabetic subjects. J Clin Invest 74: 1238-1246

5. Firth RG, Bell BM, Marsh HM, Hansen I, Rizza RA (1986) Postprandial hyperglycaemia in patients with non-insulin-dependent diabetes mellitus. J Clin Invest 77: 1525-1532 
6. DeFronzo RA, Bonadonna RC, Ferrannini E (1992) Pathogenesis of NIDDM: a balanced overview. Diabetes Care 15: 318-368

7. Katz J (1985) Determination of gluconeogenesis in vivo with ${ }^{14} \mathrm{C}$ labelled substrates. Am J Physiol 248:R391-R399

8. Consoli A, Nurjhan N, Capani F, Gerich J (1989) Predominant role of gluconeogenesis in increased hepatic glucose production in NIDDM. Diabetes 38: 550-557

9. Consoli A, Nurjhan N, Capani F, Pangburn T, Lapenna D, Gerich J (1993) Limitations in the use of $\left[2-{ }^{14} \mathrm{C}\right]$-acetate for measuring gluconeogenesis in vivo. Diabetes 42: 732-737

10. Rothman DL, Magnusson I, Katz LD, Shulman RG, Shulman GI (1991) Quantitation of hepatic glycogenolysis and gluconeogenesis in fasting humans with ${ }^{13} \mathrm{C}$ NMR. Science 254: 573-576

11. Magnusson I, Rothman DL, Katz LD, Shulman RG, Shulman GI (1992) Increased rate of gluconeogenesis in type II diabetes mellitus. A ${ }^{13} \mathrm{C}$ nuclear magnetic resonance study. J Clin Invest 90: 1323-1327

12. Consoli A, Nurjhan N, Reilley JJ, Bier DM, Gerich JE (1990) Mechanism of increased gluconeogenesis in non-insulin-dependent diabetes mellitus. J Clin Invest 86: 2038-2045

13. Zawadzki JK, Wolfe RR, Mott DM, Lillioja S, Howard BV, Bogardus C (1988) Increased rate of Cori cycle in obese subjects with NIDDM and effect of weight reduction. Diabetes 37: 154-159

14. Rossetti L, Giaccari A, Barzilai N, Howard K, Sebel G, Hu M (1993) Mechanism by which hyperglycaemia inhibits hepatic glucose production in conscious rats. J Clin Invest 92: 1126-1134

15. Saccà L, Hendler PE, Sherwin RS (1979) Hyperglycaemia inhibits glucose production in man independent of changes in glucoregulatory hormones. J Clin Endocrinol Metab 47: 1160-1163

16. Shulman GI, Lacy WW, Lijenquist JE, Keller U, Williams PE, Cherrington AD (1980) Effect of glucose, independent of changes in insulin and glucagon secretion, on alanine metabolism in the conscious dog. J Clin Invest 62: 487-491

17. Bell PM, Firth RG, Rizza RA (1986) Effect of hyperglycaemia on glucose production and utilization in humans: measurements with $\left[2-{ }^{3} \mathrm{H}\right]-,\left[3-{ }^{3} \mathrm{H}\right]$, and $\left[6-{ }^{14} \mathrm{C}\right]$-glucose. Diabetes 35: 642-648

18. Ader M, Pacini G, Ysug YJ, Bergman RN (1985) Importance of glucose per se on intravenous glucose tolerance: comparison of the minimal model prediction with direct measurements. Diabetes 34 : 1092-1103

19. Karlander S, Roovete A, Vranic M, Efendic S (1986) Glucose and fructose-6-phosphate cycle in humans. Am J Physiol 251:E530E536

20. Hue L (1987) Gluconeogenesis and its regulation. Diabetes Metab Rev 3: $111-126$

21. Williamson JR, Browning ET, Scholz R (1969) Control mechanisms of gluconeogenesis and ketogenesis. J Biol Chem 244: 4607-4616

22. Raskin P, Fujita Y, Unger RH (1975) Effect of insulin-glucose infusions on plasma glucagon levels in fasting diabetics and nondiabetics J Clin Invest 56: 1132-1138

23. Del Prato S, Enzi G, Vigili de Kreutzenberg S et al. (1990) Insulin regulation of glucose and lipid metabolism in massive obesity. Diabetologia 33: 228-236

24. Rossetti L, Smith D, Schulman G, Papachristou D, De Fronzo RA (1987) Correction of hyperglycaemia with phlorizin normalizes tissue sensitivity to insulin in diabetic rats. J Clin Invest 79: 1510-1515

25. Lisato G, Cusin I, Tiengo A, Del Prato S, Jeanrenaud B (1992) The contribution of hyperglycaemia and hypoinsulinaemia to the insulin resistance of streptozotocin-diabetic rats. Diabetologia 35: 310315

26. Rossetti L, Giaccari A, DeFronzo RA (1990) Glucose toxicity. Diabetes Care 13: 610-630

27. Rossetti L, Giaccari A (1990) Relative contribution of glycogen synthesis and glycolysis to insulin-mediated glucose uptake. A dose-response euglycaemic clamp study in normal and diabetic rats. J Clin Invest 85: 1785-1792

28. Smith D, Rossetti L, Ferrannini E et al. (1987) In vivo glucose metabolism in the awake rat: tracer and insulin clamp studies. Metabolism 36: 1176-1186
29. Rossetti L, Giaccari A, Klein-Robbenhaar E, Vogel LR (1990) Insulinomimetic properties of trace elements and characterization of their in vivo mode of action. Diabetes 39: 1243-1250

30. Rossetti L, Frontoni S, Dimarchi R, DeFronzo RA, Giaccari A (1990) Metabolic effects of insulin-like growth factor-I in diabetic rats. Diabetes 40: 444-448

31. Giaccari A, Rossetti L (1992) Predominant role of gluconeogenesis in the hepatic glycogen repletion of diabetic rats. J Clin Invest 89: $36-45$

32. Foglia VG (1944) Caracteristicas de la diabetes en la rata. Rev Soc Argent Biol 20: 21-37

33. Bonner-Weir S, Trent DF, Weir GC (1983) Partial pancreatectomy in the rat and subsequent defect in glucose-induced insulin release. J Clin Invest 71: 1544-1553

34. Giaccari A, Morviducci L, Zorretta D et al. (1995) In-vivo effects of glucosamine on insulin secretion and insulin sensitivity in the rat. Possible relevance to the maladaptive responses to chronic hyperglycaemia. Diabetologia 38: 518-524

35. Stumvoll M, Welle S, Chintalapudi U, Perriello G, Gutierrez O, Gerich J (1995) Uptake and release of glucose by the human kidney: postabsorptive rates and responses to epinephrine. J Clin Invest 96: 2528-2533

36. Stumvoll M, Meyer C, Mitrakou A, Nadkarni V, Gerich J (1997) Renal glucose production and utilization: new aspects in humans. Diabetologia 40: 749-757

37. Ekberg K, Landau BR, Efendic S, Wajngot A, Wahren J (1997) Undetectable contribution by kidney to glucose production in postabsorptive state and $60 \mathrm{~h}$ fasted states. Diabetologia 40 [Suppl 2]:A247 (Abstract)

38. Michal G (1985) Carbohydrates. In: Bergmeyer NU (ed) Methods of enzymatic analysis. Vol. VI, VCH Publishers, Weinheim, pp 191-198

39. Giaccari A, Rossetti L (1989) Isocratic high-performance liquid chromatographic determination of the concentration and specific radioactivity of phosphoenolpyruvate and uridine diphosphate glucose in tissue extracts. J Chromat 497: 69-78

40. Mueckler M (1990) Family of glucose trasporter genes. Implications for glucose homeostasis and diabetes. Diabetes 39: 6-11

41. Oka Y, Asano T, Shibasaki Y et al. (1990) Increased liver glucosetransporter protein and mRNA in streptozotocin-induced diabetic rats. Diabetes 39: 441-446

42. Yamamoto T, Fukumoto H, Koh G et al. (1991) Liver and musle-fat type glucose transporter gene expression in obese and diabetic rats. Biochem Biophys Res Commun 175: 995-1002

43. Asano T, Katagiri H, Tsukuda K, Lin J-L, Ishihara H, Yazaki Y, Oka Y (1992) Upregulation of GLUT2 mRNA by glucose, mannose and fructose in isolated rats hepatocytes. Diabetes 41: 22-25

44. Leturque A, Postic C, Burcelin R, Pegorier JP, Loizeau M, Girard J (1992) Regulation by insulin and glucose of GLUT2 mRNA in rat liver: in vivo and in vitro studies. Diabetes 41 [Suppl 1]:44A (Abstract)

45. Burcelin R, Eddouks M, Kandé J, Assan R, Girard J (1992) Evidence that GLUT2 mRNA and protein concentration are decreased by hyperinsulinaemia and increased by hyperglycaemia in the liver of diabetic rats. Biochem J 288: 675-679

46. Liu Z, Gardner LB, Barrett EJ (1993) Insulin and glucose suppress hepatic glycogenolysis by distinct enzymatic mechanisms. Metabolism 42: 1546-1551

47. Lavoie L, Dimitrakoudis D, Marette A et al. (1993) Opposite effects of hyperglycaemia and insulin deficiency on liver glycogen synthase phosphatase activity in the diabetic rat. Diabetes 42: 363366

48. Puhakainen I, Koivisto VA, Yki-Yärvinen H (1991) No reduction in total hepatic glucose output by inhibition of gluconeogenesis with ethanol in NIDDM patients. Diabetes 40: 1319-1327

49. Puhakainen I, Yki-Yärvinen H (1993) Inhibition of lipolysis decreases lipid oxidation and gluconeogenesis from lactate but not fasting hyperglycaemia or total hepatic glucose production in NIDDM. Diabetes 42: 1694-1699 